\title{
FROM HERE TO SUSTAINABILITY
}

\author{
Martin A. Hubbe \\ Many readers and contributors to BioResources are working to develop \\ sustainable technology. Such research attempts to use products of \\ photosynthesis to meet long-term human needs with a minimum of \\ environmental impact. Archeological and historical studies have \\ concluded that the long-term success or failure of various past \\ civilizations has depended, at least in part, on people's ability to maintain \\ the quality of the resources upon which they depended. Though it is \\ possible for modern societies to learn from such examples, modern \\ societies are interconnected to an unprecedented degree. It is no longer \\ realistic to expect one region to be immune from the effects of \\ environmental mistakes that may happen elsewhere in the world. \\ Research related to renewable, lignocellulosic resources is urgently \\ needed. But in addition to the research, there also needs to be \\ discussion of hard-hitting questions, helping to minimize the chances of \\ technological failure. The next failed civilization may be our own.
}

Keywords: Sustainability, Depletion, Civilizations, Renewable resources

Contact information: Department of Forest Biomaterials Science and Engineering, Campus Box 8005, Raleigh, NC27695-8005,USA; hubbe@ncsu.edu

\section{Future Generations}

"Sustainability" means that all of us live and work in such a way that our children's children can enjoy lives filled with health, nourishment, and prospects for a bright future. Briefly stated, our society must find ways to support human welfare without depleting natural resources or polluting the environment.

Our present society has not yet earned the right to be called "sustainable." We are depending on nonrenewable resources such as oil, coal, and natural gas. Many readers of BioResources are personally involved with research that seeks to use renewable resources as a much larger part of our lives and our economy. Some parts of this journey "from here to sustainability" lie beyond the bounds of what scientists can do by themselves. Rather, prudent political decisions will be required - even a change in the mindset of people throughout the world. We are starting to see that change in attitude, as people awaken to the impacts of global warming and the coming end of cheap oil.

\section{Humanity's Grand Experiments}

Consider what can happen when groups of humans fail to live in harmony with the Earth. The book Guns, Germs, and Steel by Jared Diamond provides stunning examples of the fate of such groups. Humans have been experimenting for roughly 10.5 thousand years with substantial alterations to the natural environment. Some agricultural practices have been sustained for many centuries, providing a relatively stable symbiosis between people and the land. In other cases, the land became depleted of nutrients, and 
societies disappeared. With advances in science we are coming closer to explaining why some ancient societies were able to live compatibly with the environment, whereas others tended to spoil their surroundings.

The experiment continues, but our human society has become global. It is no longer practical or morally acceptable just to move to new land. Rather, there are some hard questions that scientists and engineers need to ask. In theory, efforts to achieve sustainable lifestyles and sustainable manufacturing practices will contribute to a bright future for the world's citizens and their children's children. But if we get things wrong, as technologists, our mistakes will be at a global scale.

\section{Hard Questions}

Part of the role of journal such as BioResources is to provide a forum where scientists and engineers can exchange ideas in an effort to "get it right." Each of us probably can think of ideas that seemed great on paper, but which failed miserably upon execution. Let's ask each other some hard questions regarding ways in which efforts to build a truly sustainable economic infrastructure might fail:

- Is my research leading in the direction of a sustainable technological infrastructure?

- Is my work leading in the direction of products that are long-lasting, or at least can be recycled, composted, or safely incinerated to recover their energy value?

- Are the results of my research likely to be politically acceptable to large majorities of people, such that they stand a good chance of being implemented? Am I able to justify the technology to people having widely different political standpoints?

- Can the results of my research be implemented on a suitably small scale, so that their success does not require wasteful transportation of materials over long distances?

- Is it likely that the results of my work will lead to technology that does not depend on toxic herbicides, solvents, or increased demands for fresh water?

- Have I considered environmental implications of the "lifecycle" of materials, assuming that the technology that I am working on were to become implemented? Is the technology close to being carbon-neutral? Can it be energy-frugal?

- Am I being sufficiently bold in my research, helping to bring about changes that are sufficiently rapid that they can have a positive impact on such issues as global warming, human need, and the depletion of non-renewable resources?

- Are we designing a technological infrastructure that will tend to remove the motivations and opportunities for future wars?

Some of these questions are admittedly huge in scope, and we do not presume to provide answers to all of them in our journal. As is made abundantly clear in the pages of Guns, Germs, and Steel, humans can be very clever in figuring out ways to make civilizations survive. They also can be very stupid. In looking over published work, I have been struck by the inventiveness and global insight of authors and members of the Editorial Board of BioResources. I am convinced that we humans have what it takes to come up with ideas. My concern, though, is that we apply sufficient discussion of those ideas. We need to discuss which of them ought to be included as part of what may be humanity's final experiment in taking care of our earthly environment. We are honored here at BioResources to do our small part in this grand experiment. 